\title{
Studies in Educational Learning Environments
}

An International Perspective 
This page is intentionally left blank 


\section{Studies in Educational Learning Environments}

\section{An International Perspective}

Edited by

Swee Chiew Goh Myint Swe Khine

National Institute of Education

Nanyang Technological Universily

Singapore 
Published by

World Scientific Publishing Co. Pte. Ltd

P O Box 128, Farrer Road, Singapore 912805

USA office: Suite 1B, 1060 Main Street, River Edge, NJ 07661

UK office: 57 Shelton Street, Covent Garden, London WC2H $9 \mathrm{HE}$

\section{British Library Cataloguing-in-Publication Data}

A catalogue record for this book is available from the British Library.

\section{STUDIES IN EDUCATIONAL LEARNING ENVIRONMENTS An International Perspective}

Copyright (c) 2002 by World Scientific Publishing Co. Pte. Ltd.

All rights reserved. This book, or parts thereof, may not be reproduced in any form or by any means, electronic or mechanical, including photocopying, recording or any information storage and retrieval system now known or to be invented, without written permission from the Publisher.

For photocopying of material in this volume, please pay a copying fee through the Copyright Clearance Center, Inc., 222 Rosewood Drive, Danvers, MA 01923, USA. In this case permission to photocopy is not required from the publisher.

ISBN 981-238-145-7

ISBN 981-238-056-6 (pbk) 


\title{
Foreword
}

\author{
S. Gopinathan \\ National Institute of Education \\ Nanyang Technological University \\ Singapore
}

There is increasing recognition that many of the school reform initiatives currently under way in school systems everywhere will depend for their success on how well teachers and policymakers understand the classroom environments in which learning and teaching take place. A burgeoning literature has emerged which provides insights and data on such relationships as links between classroom environments and patterns of student learning, and the impact of innovations in curriculum and teaching strategies on learning. Researchers have also recognised that different disciplines and their particular ways of knowing reality will impose different demands upon learning environments. It can confidently be said that a robust knowledge base exists that will prove valuable in teacher preparation and professional development courses and policy making that seeks enhanced student achievement.

This volume Studies in Educational Learning Environments: An International Perspective represents an exciting advance in that it brings into one volume work by some of the leaders in the field, notably Barry Fraser, cross-cultural approaches and recent work from such Asian countries as Singapore, Taiwan, Korea and Brunei. The influence of culture is deservedly given an important place in these studies and will contribute to the emergence of models for classroom environment studies that will, by remaining sensitive to cultural variation, have greater explanatory power.

The co-editors, Swee Chiew Goh and Myint Swe Khine, are to be congratulated for their initiative and efforts in preparing this volume. Their efforts will, I am sure, be amply rewarded when learning environments research is more and more utilised in improving schooling. 
This page is intentionally left blank 


\title{
Preface
}

\author{
Barry J. Fraser \\ Curtin University of Technology \\ Australia
}

\begin{abstract}
"Constructive educational climates may be so vitally important that priorities should be drastically rearranged." (Riorden, 1982, p. 310)
\end{abstract}

This book is devoted to conceptualising, assessing and investigating what happens to students during their school and university education. In particular, the main focus is on important aspects of classroom learning environments. Clearly, having positive classroom environments is a valuable goal of education. But, it should not be assumed that the equally important issue of student outcomes is ignored. Rather, this book presents compelling evidence that the classroom environment so strongly influences student outcomes that it should not be ignored by those wishing to improve the effectiveness of schools and universities.

The curriculum of schools and universities consists not just of content and outcomes, but also of classrooms where the business of learning takes place. It is the quality of life lived in classrooms that determines many of the things that we hope for from education. As this book clearly shows, classroom climate can be assessed and studied. In fact, remarkable progress has been made in conceptualising, assessing and researching it.

In particular, over the years, researchers have developed quite a few questionnaires to assess students' perceptions of their classroom learning environments. These questionnaires have been used in different countries and at different grade levels. They have been translated into various languages. They have been used by hundreds of researchers, thousands of teachers and millions of students around the world.

Given the ready availability of questionnaires, the importance of classroom environment, the influence of classroom environment on 
student outcomes, and the value of environment assessments in guiding educational improvement, it seems very important that researchers and teachers give it greater priority. Although educators around the world pay great attention to student achievement and only a little attention to the environment of school and university classrooms, research on classroom environment should not be buried under a pile of achievement tests. Hopefully, this timely book will encourage and guide important research and practical applications involving classroom environment, especially in Asian countries. 


\section{From The Editors}

This book on educational learning environments is conceptualised as a platform for researchers and educators to share the results of their work with others who are interested in the field of Learning Environments Research (LER). It is also hoped that the book, in bringing together recent research conducted in various parts of the world, will help consolidate the achievements and developments of the field for the past 30 years.

\section{Background to LER}

Historically, learning environments research began to attract attention from the late 1960 s with the much publicised work of firstly, H.J. Walberg and colleagues in connection with the Harvard Physics Project and secondly, the work of R.H. Moos in clinical and family therapy that was later extended to education. The efforts of Walberg and Moos pioneered many major research studies in perceptions of classroom environments from the 1970s. There emerged a distinct tradition of research on students' perceptions of their classroom environment. The studies of B.J. Fraser and his associates in Australia, particularly the studies in science classrooms, contributed to the momentous growth of LER. In The Netherlands, Th. Wubbels and his colleagues worked on the model of teacher interpersonal behaviour to explain the significance of teacher-student relationship in the classrooms. Past research on classroom learning environments has been accompanied by the development and validation of several instruments over the last 30 years and these instruments formed the backbone of all studies in learning environments. Thus, LER has evolved into a field of study providing alternatives to explain students' learning success other than through students' examination performance.

As LER is carried out in many countries, it is our pleasant task to invite prominent scholars and educators from all over the world to contribute each a chapter on the research in their respective countries. This gives the book its international outlook. We would like to express our thanks to all the contributors for responding to this call of 'duty' and for making this book a reality. It is the oniy one of its kind and this book is our joint achievement. 


\section{Organisation of book}

This book is organised in a special way. It contains 10 chapters. The first chapter is written by Professor Barry J. Fraser, a distinguished name linked to learning environments research. He has been greatly involved in the field for many years and is the best person to write on "Learning Environments Research: Yesterday, Today and Tomorrow". The chapter offers insights that will set directions and stimulate further growth in LER.

The remaining nine chapters are devoted to LER in nine countries. Each chapter presents LER in the context of the country concerned and is unique in its own way. Chapters 2 to 5 present LER in Australia, Canada, The Netherlands and the USA. Chapters 6 to 10 highlight LER in the Asian countries of Brunei, Indonesia, Korea, Singapore and Taiwan. Owing to restraints, studies documented in the various chapters are not exhaustive of LER carried out in their respective countries.

Currently, research in Asian countries is gaining impetus and this prompts the authors to not only present the significant findings of their research but also provide information on the educational systems in their countries. The "What is Happening in this Class" (WIHIC) questionnaire is used in a number of Asian studies and this book has the privilege of including translated versions of the WIHIC in the Indonesian, Korean and Chinese languages. This will enhance the understanding of learning environments in different educational, social and cultural contexts. All the LER documented in the chapters bear testimony to a vibrant field and it is no wonder that there are increasing publications and conference presentations at international levels. LER has attained a level of distinction in the field of educational research that we are all proud of.

We would also like to express our thanks to the Dean of Foundation Programmes, National Institute of Education, Professor S. Gopinathan, for his unstinting support throughout the publication of this book.

Indeed, we extend our big thank you to everyone who has assisted in the publication of the book.

Swee Chiew Goh

Myint Swe Khine

National Institute of Education

Nanyang Technological University

Singapore 


\section{About The Contributors}

Jill M. Aldridge obtained her $\mathrm{PhD}$ from Curtin University of Technology, Australia. She collaborated with Professors Yang J.H. and Iris Huang in the cross-national study of learning environments in science classrooms in Taiwan and Australia.

Mieke Brekelmans is Associate Professor in a teacher training and educational research group of the Institute of Education (IVLOS) at Utrecht University (The Netherlands). Her research is in the field of teaching and teacher education. Currently, her focus is on the relation between teacher thinking and action, and the development of teaching during the professional teacher career.

Cristobal Carambo is a high school teacher in chemistry and physical science and a teaching mentor for students from the University of Pennsylvania's graduate school of education. He holds a master's degree from Florida State University. His current research focus is on the interrelationship between student agency, inquiry learning and scientific literacy in the science classroom.

Perry den Brok is Associate Professor in a teacher training and educational research group of the Institute of Education (IVLOS) at Utrecht University (The Netherlands). His research is in the field of teaching and teacher education. Currently his focus is on multicultural and intercultural studies on classroom environments, and factors that explain differences in student perceptions of teaching.

Rowhea Elmesky is a research associate at the University of Pennsylvania where she is undertaking research on the teaching and learning of science in urban high schools. Rowhea has her graduate and undergraduate degrees in science education, including her doctorate, from Florida State University.

Darrell Fisher is with the National Key Centre for Science and Maths Education in Curtin University, Perth, Australia. Professor Fisher's 
major research interests include classroom and school environments, and curriculum issues related to science, particularly curriculum evaluation. Currently, he is the Regional Editor for Asia and Australia of Learning Environments Research: An International Journal.

Barry J. Fraser is Professor and Director of the Science and Mathematics Education Centre at Curtin University of Technology in Perth, Australia. He is co-editor of the 72-chapter International Handbook of Science Education published by Kluwer, and editor-inchief of the Kluwer journal Learning Environments Research: An International Journal. He is a fellow of the American Association for the Advancement of Science, Academy of Education, Academy of the Social Sciences in Australia and Australian College of Education. He is an eminent scholar in learning environments research.

Swee Chiew Goh is with the National Institute of Education, Nanyang Technological University, Singapore. Associate Professor Goh has been in teacher education for more than 20 years. She also undertakes supervision of Master in Education students in their research and dissertation. Her research interests include the studying of learning environment at the primary, secondary and tertiary levels and classroom management.

Iris Huang Tai-chu is a science educator from the Graduate Institute of Science Education, National Kaohsiung Normal University, Taiwan. The study of learning environments in science classrooms is one of her many research interests.

Myint Swe Khine is with the National Institute of Education, Nanyang Technological University, Singapore, where he teaches courses in classroom management, IT integration and instructional design at both undergraduate and postgraduate levels. One of his academic qualifications includes Doctor of Education from Curtin University of Technology, Australia. He has been a teacher educator for more than 20 years.

Heui Baik Kim is Professor at the Wonkwang University in Iksan, Korea. She is involved in teaching biology education courses for pre- 
service and in-service teacher education programmes. Her research interests include students' understanding of science concepts and the learning environment at secondary level.

Seon Uk Lee obtained her $\mathrm{PhD}$ from Curtin University of Technology, Australia. She is a science teacher registered at the Education Department of Western Australia and is also involved in Korean language teaching.

Eko S. Margianti is Professor and President of the Gunadarma University Jakarta, Indonesia. She is the Secretary-General of Indonesia Computer Society, the Chairperson of Funding and Development of Indonesia Private Association, Vice-President of Private Indonesia Tertiary Study of Computer Association, Board Member of SEARCC IT Professional Council in South East Asia and Chairperson of Computer Education Foundation in Jakarta, Indonesia.

Kenneth Tobin is Professor of Education in the Graduate School of Education at the University of Pennsylvania. His research interests are focussed on the teaching and learning of science in urban schools and coteaching as a way of learning to teach in urban high schools. His recent publications include three co-authored books, Re/Constructing Elementary Science, At the Elbow of Another: Learning to Teach by Coteaching and Transforming Undergraduate Science Teaching: Social Constructivist Perspectives.

Bruce Waldrip has completed a great deal of research in classroom learning environment, especially in the science laboratory classroom and its relationship with learning outcomes, effect of culture on student learning, and teachers' and students' perceptions of their school-level environments. Currently, he is a senior lecturer in science education at La Trobe University, Bendigo campus, Victoria, Australia.

Theo Wubbels is Professor of Education and Director of the Institute of Educational Studies in the School of Social Sciences of Utrecht University (The Netherlands). He specialises in social psychology in education, teacher thinking and action. 
Jong-Hsiang Yang is Professor of Science Education, National Taiwan Normal University, Taiwan. He organised the 2000 Second International Conference on Science, Mathematics and Technology Education at the NTNU, Taiwan, under the co-sponsorship of Curtin University of Technology, Australia. Professor Yang is a pioneer on qualitative research methodology in science education in Taiwan.

David B. Zandvliet is with the Faculty of Education, Simon Fraser University, Vancouver, Canada. He is Director of the faculty's Centre for Educational Technology over the past three years and has been deeply involved in teacher education. His research interests lie in the areas of science, technology and environmental education with a focus on students' perceptions of their learning environment. 


\section{Contents}

Foreword $\quad$ v

Preface vii

From the Editors $\quad$ ix

About the Contributors $x i$

Chapter 1

Learning Environments Research: Yesterday, Today and

Tomorrow

Barry J. Fraser

\section{Chapter 2}

Measuring Culturally Sensitive Factors of Classroom Learning Environments with the CLEQ

Darrell L. Fisher and Bruce G. Waldrip

\section{Chapter 3}

Learning Environments in Technology-Rich Classrooms

David B. Zandvliet

\section{Chapter 4}

Teacher Experience and the Teacher-Student Relationship

in the Classroom Environment

Mieke Brekelmans, Theo Wubbels and Perry den Brok

\section{Chapter 5}

Learning Environments in Urban Science Classrooms:

Contradictions, Conflict and Reproduction of Social Inequality

Kenneth Tobin, Rowhea Elmesky and Cristobal Carambo 


\section{Chapter 6}

Study of Learning Environment for Improving Science

Education in Brunei

Myint Swe Khine

\section{Chapter 7}

Learning Environment Research in Indonesia

Eko S. Margianti

\section{Chapter 8}

Curriculum Development and Learning Environment

Research in Korea

Seon Uk Lee and Heui Baik Kim

\section{Chapter 9}

Studies on Learning Environments in Singapore Classrooms

Swee Chiew Goh

\section{Chapter 10}

Investigating Factors that Prevent Science Teachers from

Jong-Hsiang Yang, Iris Tai-Chu Huang and Jill M. Aldridge

Selected Bibliography

Index 